\title{
Evidence-based medicine and Web 2.0: friend or foe?
}

To allow for timely translation of information into clinical practice, evidencebased medicine (EBM) requires mechanisms to retrieve all relevant available data. ${ }^{1}$ In addition to databases such as PubMed and other traditional online resources, the tools and technologies built around so-called usergenerated content, collectively termed Web 2.0, provide for the efficient spreading and distribution of health information. Data suggest that almost $90 \%$ of physicians use Web 2.0 tools in their medical practice while few actually contribute content. ${ }^{2}$ About $75 \%$ of internet users including patients have looked online for health information in the past. ${ }^{3,4}$ As the easily accessible information available to the healthcare user may strengthen the doctor-patient relationship and empower patients, ${ }^{5}$ it may also introduce bias into the practice of EBM (Figure 1). In particular, the nature of social media and the Web 2.0 allows for a quick and completely uncontrolled environment in which information can spread whereby the provenance and trustworthiness of such sources is often not easy to determine. The aim of this article is to describe Web 2.0 technologies and its effects on medical practice.

\section{WEB 2.0}

The last few years has seen a major shift in the way people use and interact with online resources. Whereas in the early 2000 s most websites had a passive role displaying mostly static content ('pull' technologies) with very little opportunity for interaction from visitors, Web 2.0 is characterised by an interactive, participatory model ('push' technologies). Visitors to websites can comment, share, and interact with the content they encounter and in some cases can edit or re-mix the information. It is no longer the traditional publisher or expert that controls the distribution of web content; any user can now contribute and publish content.

Many of the most popular websites rely heavily on user participation. The exchange of user-generated content is facilitated via tools such as blogs, microblogs like Twitter, wikis like Wikidoc (http://www.wikidoc.org/index.php/) and other self-publishing mechanisms. In

Figure 1. Knowledge translation and practice of evidence based medicine.

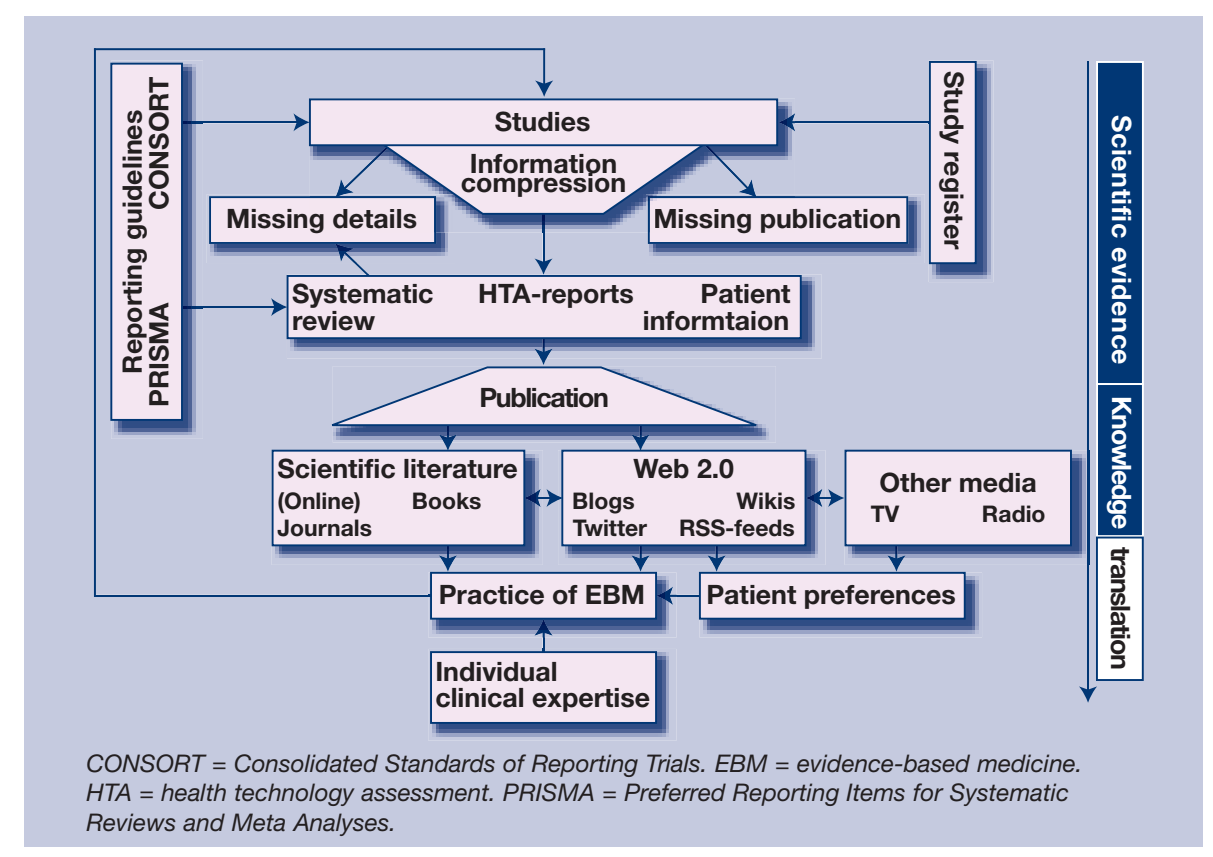

addition, the user is now in control of their own personal information flow via technologies such as RSS feeds, personalised homepages (iGoogle, Netvibes) and other content services. Most online medical resources and journals such as the Journal of Internal Medicine or PubMed are now providing RSS feeds, a technology whereby information comes to the user through various aggregation tools. In the context of health information, Web 2.0 technologies provide healthcare professionals and patients with new ways to access, share, and debate medical information at an ever-increasing speed and with a breadth that would have been impossible just 5 years ago (Box 1).

\section{DOCTOR-PATIENT RELATIONSHIP}

By providing possibilities to engage to an unprecedented degree, Web 2.0 technologies empower patients to use information for their healthcare research and to interact with other patients and clinicians. Depending on the quality of the information, patients may increase their knowledge in healthcare-related topics and gain confidence when communicating with their treating physician. Patients may also be more willing to play an active role in their healthcare decisions and make better-informed choices. In the US, for instance, integrated personal health records, whereby patients view and actively upload their own measurements such as home blood pressure readings is no longer a futuristic scenario. ${ }^{6}$ It seems that individuals who are younger, female, and better educated prefer more active participation $^{7}$ in healthcare matters, which is also corroborated in other areas of health care. ${ }^{8}$ Physicians will require strong interpersonal and communication skills when advising such active patients and may feel challenged in their authority.

Whether these developments save resources and increase the safety and quality of care is as yet unclear. ${ }^{5,6}$ What is clear, however, is that there has been a 


\section{Box 1. A typical Web 2.0 scenario.}

A patient with depression is interested in learning more about his condition and decides to search for information. He searches the internet and finds various sites which also contain a blog on the topic. This site is interesting enough for the patient to sign up for a regular update using RSS feeds. This, he hopes, will enable him to stay up-to-date with the newest information added to that blog. This patient then decides to share the information with other patients and joins a discussion group of fellow patients with depression. The discussion is intense and thought provoking which sparks another patient to briefly inform his friends using Twitter. In the meantime the original blog mentions a podcast of a leading patient interest group on depression which is now being disseminated to all participating users via RSS technology. The patient then discusses the gained information with his treating physician and expresses his preferences. In this way, the patients' therapeutic regimen is partly determined by Web 2.0. As he feeds back his own experience with his altered treatment to his original patient group, one individual experience which was altered via Web 2.0 will influence a wider group of patients via the same medium.

shift in how information is controlled and distributed. While on the one hand, this means more 'empowered' patients, often armed with evidence-based information acquired through online research and ready to challenge their physicians, on the other hand there is a significant chance for this information to be either biased, misleading, or simply incorrect.

\section{INTRODUCTION OF BIAS}

The danger of misinformation from nontrustworthy websites has risen dramatically since the inception of EBM due to the sheer speed of information now being produced and exchanged. Medical information and advice on the internet may be inaccurate or misleading. ${ }^{9}$ Many users are not able to assess the quality of websites when searching for health information $^{10}$ and are susceptible to misinformation. At the same time there are very few usable and accepted quality scales that are available to patients and healthcare providers. ${ }^{11}$ One survey suggests that about $75 \%$ of users accessing the internet for health information do not regularly check the source and the date of the information found online. ${ }^{5}$ Also, patients may not fully understand the content within websites they view and may not be able to put the information into the correct context. It is feared that inappropriate healthcare interventions advocated by websites may be requested by patients and affect evidence-based practice. It is particularly pertinent to healthcare practice that information be accurate, up-to-date, and unbiased. ${ }^{12}$ Patients and other healthcare users require education as to what constitutes reliable information on websites and need to be directed to reliable sources of information such as www.cochrane.org.

However, the shift towards Web 2.0 technologies means that people often do not even visit websites or primary sources of information at all. They encounter this information via Facebook, Twitter, on blogs via RSS feeds, and through a myriad of other mediums. The popular children's game of 'telephone', whereby a phrase is whispered to each other and the information degrades as it is transmitted, illustrates the unpredictable nature of information gathered through many Web 2.0 technologies.

Due to the nature of the Web 2.0 online landscape, it is often difficult to control the flow of content and information. Thus, determining the provenance or authority behind content posted in a discussion forum, wiki, blog or other environment creates a challenge for consumers. Often, content is taken out of context and shared or remixed into other applications and is then not necessarily reliable or accurate. A certain degree of information literacy is therefore required to be able to navigate through web-based information in general and healthcare information in particular.

As the uncontrolled nature of the Web 2.0 and social media can introduce bias, inaccuracies, and out-of-context information into the practice of EBM, the same power can be harnessed to spread accurate and reliable information. The challenge for providers of evidence-based healthcare information is to join the information exchange on the web to a greater extent than before and advise and direct the patient and other users to accurate and reliable information on the web. Thus, by providing possibilities to engage to an unprecedented degree, Web 2.0 technologies empower patients and strengthen the doctor-patient relationship. The danger of misinformation from nontrustworthy sources, however, is considerable. Patients require education to appraise the quality of online information and direction to reliable resources. It is imperative that doctors provide adequate advice and guidance to their patients.

\section{Max Pittler, Christopher Mavergames, Edzard Ernst and Gerd Antes}

\section{REFERENCES}

1 Sackett DL. Evidence-based medicine. Semin Perinatol 1997; 21: 3-5.

2 Hughes B, Joshi I, Lemonde H, Wareham J. Junior physician's use of Web 2.0 for information seeking and medical education: a qualitative study. Int J Med Inform 2009; 78: 645-55.

3 Fox S. The engaged e-patient population. http://www.pewinternet.org/Reports/2008/TheEngaged-Epatient-Population.aspx (accessed $14 \mathrm{Mar}$ 2011).

4 Kernisan LP, Sudore RL, Knight SJ. Information-seeking at a caregiving website: a qualitative analysis. $\mathrm{J} \mathrm{Med}$ Internet Res 2010; 12: e31.

5 Lo B, Parham L. The impact of web 2.0 on the doctor-patient relationship. J Law Med Ethics 2010; 38: $17-26$.

6 Tang PC, Lee TH. Your doctor's office or the Internet? Two paths to personal health records. N Engl J Med 2009; 360: 1276-1278.

7 Say R, Murtagh M, Thomson R. Patients' preference for involvement in medical decision making: a narrative review. Patient Educ Couns 2006; 60: 102-114.

8 Hunt KJ, Coelho HF, Wider B, et al. Complementary and alternative medicine use in England: results from a national survey. Int J Clin Pract 2010; 64: 1496-502.

9 Schmidt K, Ernst E. Assessing websites on complementary and alternative medicine for cancer. Ann Oncol 2004; 15: 733-742.

10 Eysenbach G, Kohler C. How do consumers search for and appraise health information on the world wide web? Qualitative study using focus groups, usability tests, and in-depth interviews. BMJ 2002; 324: 573-577.

11 Bernstam EV, Shelton DM, Walji M, Meric-Bernstam F. Instruments to assess the quality of health information on the World Wide Web: what can our patients actually use? Int J Med Inform 2005; 74: 13-9.

12 Boddy K, Ernst E. Review of reliable information sources related to integrative oncology. Hematol Oncol Clin North Am 2008; 22: 619-30, vii.

DOI: 10.3399/bjgp11X567342 